Available online at http://jurnal.goretanpena.com/index.php/JSSR

\title{
PEMETAAN LOKASI NASABAH KREDITUR MACET BERBASIS SISTEM INFORMASI GEOGRAFIS
}

\author{
Andri Nata ${ }^{1}$, Sri Rafika Dewi ${ }^{2}$, Edi Kurniawan ${ }^{3}$ \\ STMIK Royal, Kisaran \\ e-mail: ${ }^{1}$ andrinata0202@ gmail.com, ${ }^{2}$ dewikisaran26@gmail.com, \\ 3edikurniawan@royal.ac.id
}

\begin{abstract}
PT Anugerah Karya Abiwara 1 serves Honda motorcycle sales both cash and credit, motorcycle spare parts sales and motorcycle service in Kisaran City. PT Anugerah Karya Abiwara has many bad creditor customers at PT Anugerah Karya Abiwara in 2019 which are located in various areas in Asahan Regency. The incomplete information about the customer's home address makes it difficult for collectors to find the location of the bad and bad creditor's customer's house properly and correctly. Based on these problems, a geographic information system is needed that makes it easier for Anugerah Karya Abiwara collectors to find the location of bad creditor customers and make it easier for the collection process for arrears. To assist and minimize the time of Anugerah Karya Abiwara collectors in finding information on the location of the home address of bad creditor customers, we need a geographic information system that can be easily accessed. The purpose of this study is to design an application for mapping the location of bad creditor customers using GIS which is expected to help collectors find bad creditor customers. As for designing this application using the PHP programming language and MySQL database. The results of this study collectors will easily find the location of the customer's address to be addressed, which is Anugerah Karya Abiwara which provides the location of the address based on coordinates equipped with accurate travel routes.
\end{abstract}

Keywords: Geographic Information System, Customers, Anugerah Karya Abiwara

\begin{abstract}
Abstrak: PT Anugerah Karya Abiwara 1 melayani penjualan sepeda motor honda baik cash maupun kredit, penjualan spare part sepeda motor dan service sepeda motor di Kota Kisaran. PT Anugerah Karya Abiwara mempunyai banyak nasabah kreditur macet di PT Anugerah Karya Abiwara tahun 2019 yang terletak di berbagai wilayah di Kabupaten Asahan. Kurang lengkapnya informasi tentang alamat rumah nasabah mengakibatkan kolektor kesulitan untuk menemukan lokasi rumah nasabah kreditur macet dengan baik dan benar. Berdasarkan permasalahan tersebut maka dibutuhkan suatu sistem informasi geografis yang mempermudah kolektor Anugerah Karya Abiwara dalam mencari lokasi nasabah kreditur macet dan memudahkan untuk proses penagihan tunggakan. Untuk membantu dan meminimalisir waktu kolektor Anugerah Karya Abiwara dalam menemukan informasi lokasi alamat rumah nasabah kreditur macet,. Tujuan penelitian ini merancang aplikasi pemetaan lokasi nasabah kreditur macet menggunakan GIS yang diharapan dapat membantu para kolektor untu mencari nasabah kreditur macet. Hasil dari penelitian ini koletor akan mudah mencari lokasi alamat nasabah yang hendak dituju yang mana Anugerah Karya Abiwara yang menyediakan lokasi alamat tersebut berdasarkan titik koordinat yang dilengkapi dengan rute perjalanan yang akurat.
\end{abstract}

Kata kunci: Sistem Informasi Geografis, Nasabah, Anugerah Karya Abiwara. 
Available online at http://jurnal.goretanpena.com/index.php/JSSR

\section{PENDAHULUAN}

PT Anugerah Karya Abiwara 1 terletak di jalan Sisingamangaraja No. 320 A-E Kisaran yang melayani pembeli penjualan sepeda motor honda baik cash maupun kredit, penjualan spare part sepeda motor dan servis sepeda motor. Saat ini PT Anugerah Karya Abiwara 1 mempunyai banyak nasabah kreditur macet yang susah untuk membayar iuran bulanan sepeda motor sehingga membuat kolektor mengalami permasalahan tunggakan yang banyak dan kesulitan mencari lokasi rumah nasabah kreditur macet sehingga semakin sulit untuk melakukan penagihan pembayaran iuran sepeda motor. Berdasarkan permasalahan tersebut maka dibutuhkan suatu sistem informasi geografis yang mempermudah PT Anugerah Karya Abiwara 1 dalam mencari lokasi nasabah kreditur macet dan memudahkan untuk proses penagihan tunggakan. Karena dengan sistem yang lama kolektor PT Anugerah Karya Abiwara 1 harus bertanya kepada orang sekitar mengenai informasi lokasi rumah nasabah kreditur macet. Hal ini akan membuang banyak waktu dalam mencari dan menemukan lokasi alamat rumah tersebut. Untuk membantu dan meminimalisir waktu masyarakat dalam menemukan informasi lokasi alamat rumah nasabah kreditur macet, dibutuhkannya suatu sistem informasi geografis yang dapat diakses secara mudah oleh kolektor.

Sistem informasi geografi ini berfungsi untuk menyimpan data dan Menyembunyikan informasi geografis. Perancangan sistem informasi geografis mendukung untuk mengumpulkan, menyimpan, dan menganalisis objek-objek dimana lokasi geografi merupakan karakteristik yang penting untuk di teliti. Sistem informasi geografis merupakan sistem komputer yang memiliki kemampuan yaitu masukan, manajemen data, analisis dan manipulasi data, dan keluaran[1].

Sistem informasi geografis Menyatukan titik koordinat yang ada pada peta atau keberadaan kita dengan menggabungkannya, menganalisa, dan akhirnya menentukan hasilnya. Contohnya seperti data Spesial[2][3].

Hasil dari pengembangan sistem informasi geografis ini, akan ditampilkan data berupa biodata nasabah kreditur macet, alamat rumah, dan gambar rumah. Sistem geografis ini berbasis web, kolektor dapat mengakses informasi secara online untuk mempercepat pencarian alamat nasabah kreditur macet.

\section{METODE}

Metode penelitian yang digunakan adalah penelitian kualitatif. Merupakan penelitian yang hanya mengumpulkan data dan menjelaskan secara deskripstif/narasi tanpa harus diolah dengan pengujian statistik.

Adapun uraian kerangka kerja pada penelitian ini adalah:

1) Identifikasi Masalah

Adapun identifikasi masalah dalam penelitian ini adalah sistem yang lama kolektor PT Anugerah Karya Abiwara 1 harus bertanya kepada orang sekitar mengenai informasi lokasi rumah nasabah kreditur macet. Hal ini akan membuang banyak waktu dalam mencari dan menemukan lokasi 
Available online at http://jurnal.goretanpena.com/index.php/JSSR

alamat rumah tersebut. PT Anugerah Karya Abiwara 1 belum memiliki sistem informasi yang dapat diakses secara cepat tentang nasabah kreditur macet.

2) Perumusan Masalah

Adapun perumusan masalah dalam penelitian ini adalah

Bagaimana sistem informasi geografis pencarian alamat nasabah kreditur macet di PT Anugerah Karya Abiwara 1 yang sedang berjalan saat ini? Bagaimana merancang dan membangun sistem informasi geografis pencarian alamat nasabah kreditur macet di PT Anugerah Karya Abiwara 1?

Apakah dengan menerapkan sistem informasi geografis pencarian alamat nasabah kreditur macet di PT Anugerah Karya Abiwara 1 memudahankan proses pencarian alamat oleh kolektor?

3) Studi Kepustakaan

Beberapa judul buku yang digunakan dalam penelitian ini adalah Rekayasa Perangkat Lunak dan Dasar Pemrograman Web dengan PHP. Rancang Bangun Sistem Informasi Geografis Daerah TitikRawan Kecelakaan Di Provinsi Lampung[4], Aplikasi Sistem Informasi One Stop Pet Shop Berbasis Web Pada Golden Pet[5], Sistem Informasi Geografis (SIG) Pemetaan KostKosan Menggunakan Metode Formula Haversine[6], Sistem Informasi Geografis Menentukan LokasiPertambangan Batu Bara Di Provinsi Bengkulu Berbasis Website[7].

4) Desain Penelitian

Desain penelitian merupakan prosedur serta teknik dalam perencanaan penelitian yang berguna sebagai panduan untuk membangun strategi yang menghasilkan model penelitian.

5) Pengumpulan Data

Pengumpulan data dilakukan dengan mewawanca pimpinan PT Anugerah Karya Abiwara 1 dan karyawannya untuk memperoleh data sejarah, visi misi, struktur organisasi, uraian tugas dan data nasabah kreditur macet.

6) Analisis Data

Setelah data sudah diperoleh selanjutnya dianalisis untuk di kembangkan oleh sistem yang bertujuan mendapatkan hasil lebih baik.

7) Analisis Sistem

Analisa sistem berfungsi untuk mengetahui sistem yang ada. Analisa sistem diuji terlebih dahulu sebelum melakukan analisa permasalahan, kelemahankelemahan sistem, dan kebutuhan sistem.

8) Mendesain Sistem

Sistem didesain dengan menggunakan software Visual Paradigm untuk menggambar diagram Unified Modeling Language (UML) dan microsoft word untuk menggambar diagram alir (flowchart). Sistem di bangun dengan bahasa PHP, dan database MySQL.

9) Implementasi dan Pengujian

Pengujian dilakukan dengan menggunakan uji black box yang merupakan pengujian tomboltombol sistem. 
Available online at http://jurnal.goretanpena.com/index.php/JSSR

\section{HASIL DAN PEMBAHASAN}

Halaman utama

Berikut adalah halaman utama ketika koletor ingin membukan aplikasi tersebut

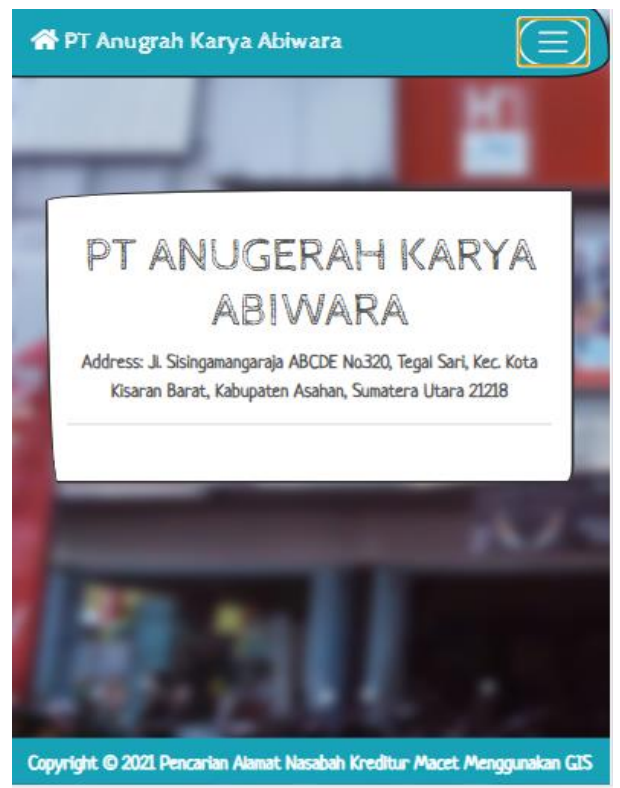

Gambar 1. Halaman Utama

Halaman List Lokasi

Berikut adalah halaman untuk list lokasi ketika kolektor hendak melihat alamat nasabah

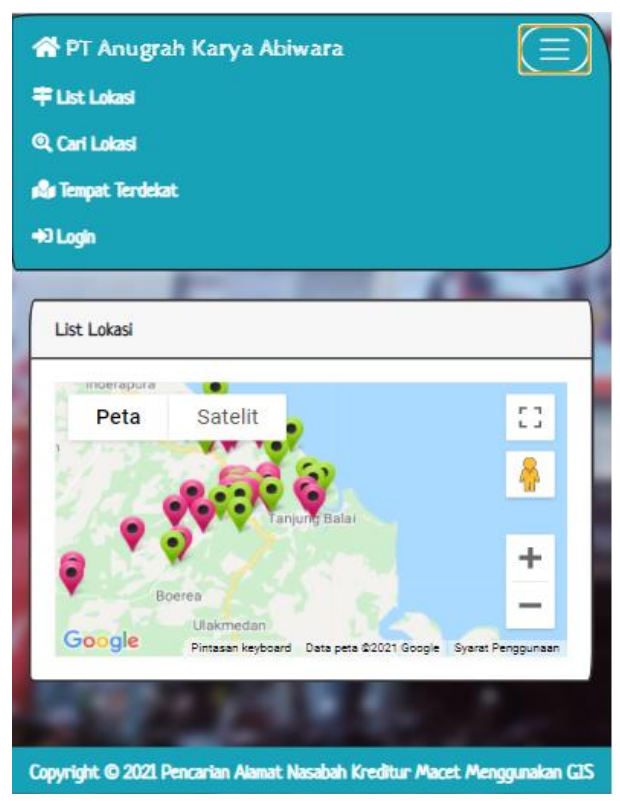

Gambar 2. Halaman List Lokasi

\section{Halaman Cari Lokasi}

Berikut adalah halaman untuk cari lokasi ketika kolektor hendak mencari alamat nasabah dengan cara mengetikkan nama nasabah maka aplikasi tersebut akan menunjukan alamat nasabah tersebut.

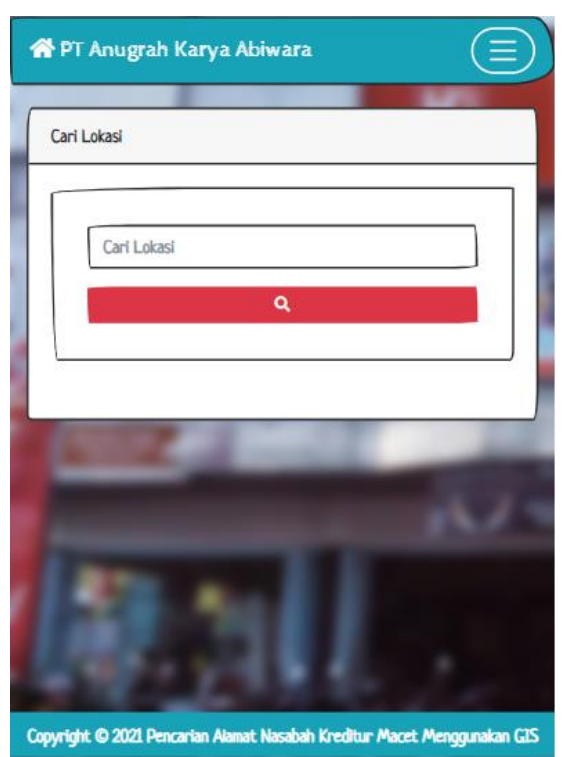

Gambar 3. Halaman Cari Lokasi

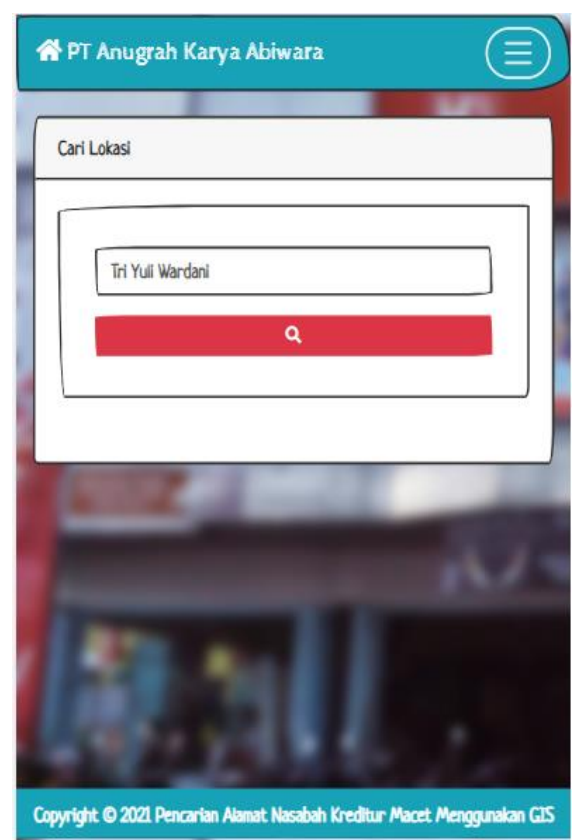

Gambar 4. Halaman Cari Lokasi Input Nama 
Available online at http://jurnal.goretanpena.com/index.php/JSSR

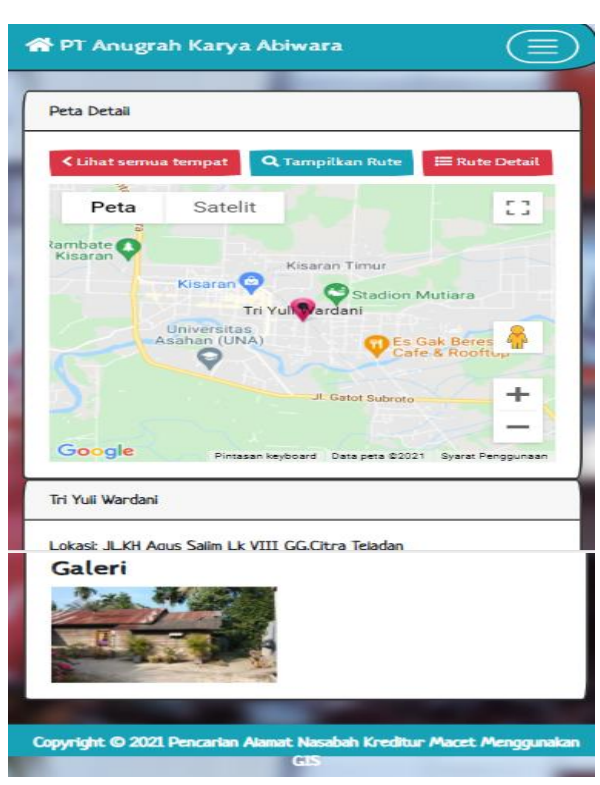

Gambar 5. Halaman Hasil Pencarian Lokasi

\section{Terdekat}

Halaman Pencarian Tempat

Berikut adalah halaman untuk cari lokasi ketika kolektor hendak mencari alamat nasabah berdasarkan tempat terdekat. Adappun pilihannya adalah 5 $\mathrm{km}, 10 \mathrm{~km}, 50 \mathrm{~km}, 100 \mathrm{~km}$, dengan cara memilih jarak nasabah maka aplikasi tersebut akan menunjukan alamat nasabah tersebut.

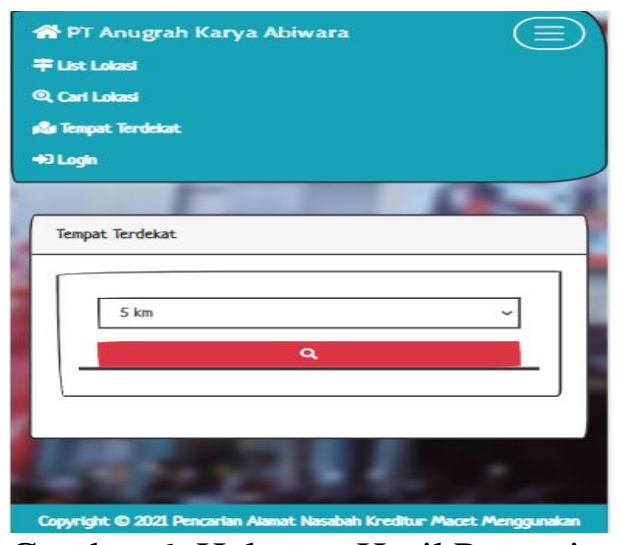

Gambar 6. Halaman Hasil Pencarian Lokasi Berdasarkan Jarak
Halaman Login Administrator Berikut adalah halaman login untuk masuk keadministrator.

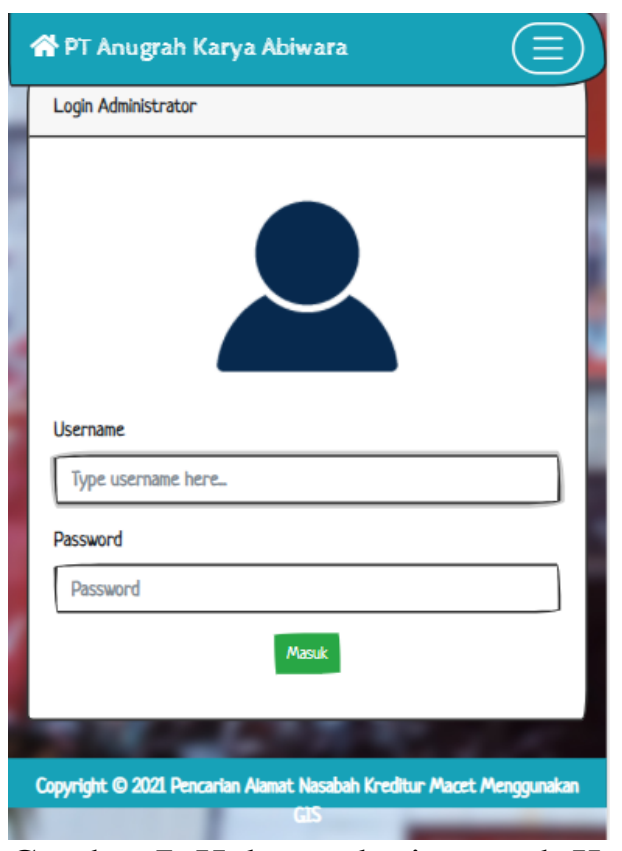

Gambar 7. Halaman login masuk Ke Menu Administrator

Halaman Administrator

Berikut adalah halaman administrator yang terdiri dari menu kategori yang terdiri dari macet dan lancar, tempat yang berisikan data nasabah, galeri yang berisikan foto yang berkaitan dengan data nasabah seperti foto rumah, password dan logout.

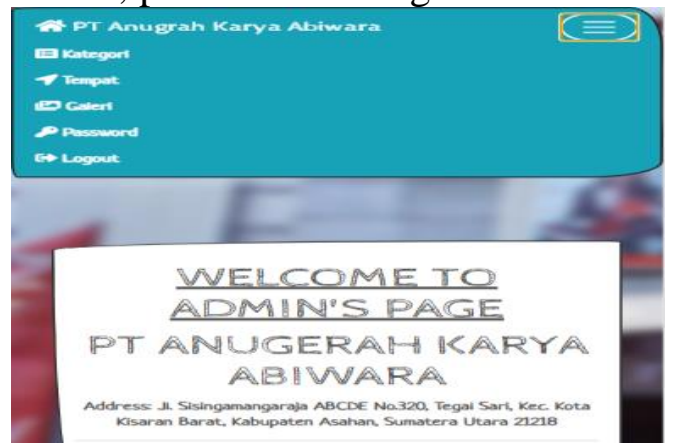

Gambar 8. Halaman Menu

Administrator 
Available online at http://jurnal.goretanpena.com/index.php/JSSR

\section{SIMPULAN}

Adapun kesimpulan dalam penelitian pencarian alamat nasabah kreditur macet menggunakan sistem informasi geografis di PT Anugerah Karya Abiwara 1 adalah:

1. Sistem yang lama kolektor PT Anugerah Karya Abiwara 1 harus bertanya kepada orang sekitar mengenai informasi lokasi rumah nasabah kreditur macet. Hal ini akan membuang banyak waktu dalam mencari dan menemukan lokasi alamat rumah tersebut.

2. Sistem pencarian alamat nasabah kreditur macet menggunakan sistem informasi geografis di PT Anugerah Karya Abiwara 1 dirancang dan dibangun dengan menggunakan bahasa pemrograman $P H P$ dan database MySQL yang berbasis web serta dapat diakses secara online dimana saja dan kapan saja melalui media internet.

2. Sistem pencarian alamat nasabah kreditur macet menggunakan sistem informasi geografis di PT Anugerah Karya Abiwara 1 dapat memudahkan kolektor untuk mengetahui tata letak lokasi dan informasi terkait alamat nasabah kreditur macet tersebut dengan menggunakan pengujian black box untuk pengujian interface.

\section{DAFTAR PUSTAKA}

[1] S. Maharani, "Sistem Informasi Geografis Pemetaan Masjid Di Samarinda Berbasis Web," $J$. Inform., vol. 11, no. 1, p. 9, 2017, doi: 10.26555/jifo.v11i1.a5205.
[2] N. R. Hasna, A. Setiawan, and H. A. Parhusip, "Penentuan Lokasi Lumbung Pangan Berdasarkan Gravity Location Models dengan Koordinat UTM di Provinsi Maluku Utara," J. Sains dan Edukasi Sains, vol. 1, no. 2, pp. $7-$ 16, 2018, doi: 10.24246/juses.v1i2p7-16.

[3] D. Umagapi, A. Ambarita, and N. F. Kharie, "Rancang Bangun Sistem Informasi Geografis Pemetaan Tanaman Pangan Kabupaten Pulau Morotai," J. Ilm. Ilk. - Ilmu Komput. Inform., vol. 3, no. 1, pp. 12-20, 2020, doi: 10.47324/ilkominfo.v3i1.39.

[4] D. Susianto and R. A. Guntoro, "Rancang Bangun Sistem Informasi Geografis Daerah Titik Rawan Kecelakaan Di Provinsi Lampung," J. Cendikia, vol. 14, no. 1, pp. 19-25, 2017.

[5] S. Setyowibowo and I. D. Mumpuni, "Aplikasi Sistem Informasi One Stop Pet Shop Berbasis Web Pada Golden Pet," J. Ilm. Teknol. Inf. Asia, vol. 10, no. 1, pp. 33-40, 2016.

[6] M. I. Sa'ad, M. Surahmanto, M. R. P. Soemari, K. K, and M. S. Mustafa, "Sistem Informasi Geografis (SIG) Pemetaan KostKosan Menggunakan Metode Formula Haversine," J-SAKTI (Jurnal Sains Komput. dan Inform., vol. 4, no. 1, p. 54, 2020, doi: 10.30645/j-sakti.v4i1.187.

[7] K. M. Wibowo, I. Kanedi, and J. Jumadi, "Sistem Informasi Geografis (SIG) Menentukan Lokasi Pertambangan Batu Bara di Provinsi Bengkulu Berbasis Website," J. Media Infotama, vol. 11, no. 1, pp. 51-60, 2015. 